BIBECHANA

Vol. 6, March 2010

\title{
EXPERIMENTAL STUDY OF FREE ENERGY OF ACTIVATION OF FLOW AND GRUNBERG-NISSAN PARAMETERS IN BINARY LIQUID MIXTURES
}

\author{
I.S.Jha ,R.P. Koirala and D. Adhikari \\ M.M.A.Campus, Biratnagar, Tribhuvan University, Nepal
}

\begin{abstract}
The binary mixtures of cabontetrachloride with isobutylmethylketone and benzaldehyde were studied at 308.15 by measuring viscosities and densities. The derived and excess viscosities, activation energy of flow and Grunberg-Nissan parameters have been calculated. It was found that these parameters are satisfactorily used to predict the strength and nature of molecular interactions. It was found that the strength of interactions in the systems studied is in the following order :

$$
\mathrm{CCl}_{4}+\mathrm{IBMK}>\mathrm{CCl}_{4}+\mathrm{BD}
$$
\end{abstract}

\section{Kewyords: Binry liquid; benzaldehyde; carbontetrachloride}

\section{Introduction}

Compressibility which is a static properly and viscosity which is a transport property, are the most useful and important amongst the properties of the liquid. Attempts have been made to relate these properties to the strength of molecular interaction through various models [1].

Excess thermodynamics parameters [2-4] and excess ultrasonic parameters [5-8)] have been used by various workers extensively in studying relative strength of intermolecular interaction in pure liquids and binary liquid mixtures. However, very few attempts [9-10] have been made to study molecular interactions through viscosity data. This work attempts to describe the interactions from the result of viscosity measurements in binary mixtures of carbontetrachloride with benzaldehyde and isobutylmethylketone at $308.15 \mathrm{~K}$.

We know due to viscosity liquids exhibits resistance to flow. In laminar flow molecules flowing ahead must acquire a definite amount of energy. This energy is called the free energy of activation of flow per mole. In general, higher the free energy of activation of flow, moiré viscous is the liquid. However, other factors are also important.

Eyring [13] developed a simple theory of liquid. He suggested that the fundamental rate process for viscous flow in liquid is the migration of molecules from a lattice site into nearby hole from which it can then move to another site. Thus work is required to make the hole against the potential barrier due to the migration of molecules and the process is therefore analogous to chemical reaction proceeding through a transition state higher energy than the initial and final states. The absolute reaction-rate of Erying [14] and co-workers relates the viscosity to the energy needed for a molecule to overcome the attractive force field of its neighbours so that it can jump (flow).

In this present work attempts have made to describe the interaction from the results of viscosity measurement of the binary mixtures.

\section{Formalism}

Free energy of activation of flow $(\mathrm{G})$ has been calculated y the following equation : 


\section{I.S. Jha et.al}

$$
\mathrm{G}=\mathrm{RT} 1_{\mathrm{n}}\left(\frac{\eta \mathrm{V}}{\mathrm{hN}}\right)
$$

Where $\mathrm{R}, \mathrm{T}, \eta, \mathrm{V}, \mathrm{h}$ and $\mathrm{N}$ are gas constant, absolute temperature, viscosity, molar volume, Plank's constant and Avogadro's number respectively.

Grunberg-Nissan parameter (d) has been calculated using following equation:

$$
\text { In } \eta=X_{1} \ln \eta_{1}+X_{2} \ln \eta_{2}+X_{1} X_{2} d
$$

Where $\eta$ is the viscosity of binary mixture, $\eta_{1}$ and $\eta_{2}$ re the viscosities of ith component of the mixtures with mole fraction $X_{1}$ and ' $d$ ' is the parameter which is regarded as a measure of the strength of interaction between the components of the mixture.

Excess parameters have been calculated using the following equation

$$
\mathrm{P}^{\mathrm{E}}=\mathrm{P}_{\text {measured }} \sum \mathrm{X}_{\mathrm{i}} \mathrm{P}_{\mathrm{i}}
$$

$\mathrm{P}_{\text {measured }}$ is the experimental measured value of the parameter $\mathrm{P}$ for the mixture and $\mathrm{P}_{\mathrm{i}}$ is the value of $\mathrm{P}$ for the ith pure liquid having $\mathrm{X}_{1}$ mole fraction in the mixture.

Comparison of experimentally measured value of the parameter $\mathrm{P}$ for the mixture and $\mathrm{P}_{1}$ is the value of $\mathrm{P}$ for the ith pure liquid having $\mathrm{X}_{1}$ mole fraction in the mixture.

$$
\mathrm{P}^{\mathrm{E}}=\mathrm{X}_{1} \mathrm{X}_{2}\left[\mathrm{~A}+\mathrm{B}\left(\mathrm{X}_{1}-\mathrm{X}_{2}\right)+\mathrm{C}\left(\mathrm{X}_{1}-\mathrm{X}_{2}\right)\right]^{2}
$$

Where $\mathrm{A}, \mathrm{B}$ and $\mathrm{C}$ are constants, determined by least square fit method. PE represents $\eta^{\mathrm{E}}, \mathrm{V}^{\mathrm{E}}$ and $\mathrm{G}^{\mathrm{E}}$ respectively for the system.

\section{Method and methodology}

The liquids carbontetrachloride $\left(\mathrm{CCl}_{4}\right)$, isobutylketone (IBMK) and benzaldehyde were of analytic grade (E-merek) and used as it was supplied. The densities and viscosities of these pure liquids were checked against the literature values published elsewhere [15]. The densities were measured using bicapillary pyknometer of $10 \mathrm{cc}$ capacity whereas the masses were measured by using electronic balance of sensitivity $0.001 \mathrm{gm}$. Viscosities were measured by Oswald's viscometer. The binary mixtures of the liquids were prepared according to normal process using mole fractions.

Table 1

(Cabontetrachloride + Benzaldehyde) $308.15 \mathrm{~K}$

\begin{tabular}{|c|c|c|c|c|c|}
\hline obs & $\mathrm{X}_{1}$ & $\mathrm{X}_{2}$ & $\eta\left(10^{-4} \mathrm{Nm}^{-2}\right)$ & $\rho\left(\mathrm{kgm}^{-3}\right)$ & $\mathrm{V}\left(10^{-6} \mathrm{~m}^{3}\right)$ \\
\hline 1 & 0.000 & 1.000 & 11.562 & 1023.610 & 103.672 \\
\hline 2 & 0.113 & 0.887 & 10.927 & 1031.350 & 108.925 \\
\hline 3 & 0.295 & 0.705 & 10.045 & 1086.920 & 107.161 \\
\hline 4 & 0.376 & 0.624 & 9.836 & 1089.660 & 111.812 \\
\hline 5 & 0.427 & 0.573 & 9.214 & 1173.540 & 110.213 \\
\hline 6 & 0.505 & 0.495 & 8.824 & 1208.290 & 112.567 \\
\hline 7 & 0.601 & 0.399 & 8.493 & 1275.520 & 109.169 \\
\hline 8 & 0.741 & 0.259 & 8.235 & 1356.910 & 105.633 \\
\hline 9 & 0.890 & 0.110 & 7.991 & 1434.170 & 104.067 \\
\hline 10 & 1.000 & 0.000 & 7.955 & 1569.140 & 98.028 \\
\hline
\end{tabular}


BIBECHANA

Vol. 6, March 2010

Table 2

(Cabontetrachloride + Isobutykmethylketone) $308.15 \mathrm{~K}$

\begin{tabular}{|c|c|c|c|c|c|}
\hline obs & $\mathrm{X}_{1}$ & $\mathrm{X}_{2}$ & $\eta\left(10^{-4} \mathrm{Nm}^{-2}\right)$ & $\rho\left(\mathrm{kgm}^{-3}\right)$ & $\mathrm{V}\left(10^{-6} \mathrm{~m}^{3}\right)$ \\
\hline 1 & 0.000 & 1.000 & 4.954 & 786.94 & 127.277 \\
\hline 2 & 0.143 & 0.857 & 5.014 & 873.62 & 123.475 \\
\hline 3 & 0.234 & 0.766 & 5.154 & 926.44 & 121.595 \\
\hline 4 & 0.333 & 0.667 & 5.282 & 961.32 & 122.805 \\
\hline 5 & 0.461 & 0.539 & 5.407 & 1037.72 & 120.394 \\
\hline 6 & 0.582 & 0.416 & 5.710 & 1119.81 & 117.345 \\
\hline 7 & 0.695 & 0.605 & 6.101 & 1270.01 & 106.265 \\
\hline 8 & 0.801 & 0.199 & 6.682 & 1324.02 & 106.599 \\
\hline 9 & 0.904 & 0.096 & 6.964 & 1446.10 & 102.812 \\
\hline 10 & 1.000 & 0.000 & 7.955 & 1569.14 & 98.028 \\
\hline
\end{tabular}

Table 3

(Cabontetrachloride + Isobutykmethylketone) $308.15 \mathrm{~K}$

\begin{tabular}{|c|c|c|c|c|c|c|}
\hline obs & $\mathrm{X}_{1}$ & $\eta^{E}\left(10^{-5} \mathrm{NSm}^{-2}\right)$ & $V^{E}\left(10^{6} \mathrm{~m}^{3}\right)$ & $\mathrm{G}(\mathrm{KJ} / \mathrm{mole})$ & $G^{E}(\mathrm{KJ} /$ mole $)$ & $\mathrm{d}$ \\
\hline 1 & 0.000 & 0.000 & 0.00 & 13.02 & 0.00 & 0.000 \\
\hline 2 & 0.143 & -6.701 & 0.46 & 12.97 & -28.68 & -0.439 \\
\hline 3 & 0.234 & -5.038 & 1.27 & 13.01 & -31.88 & -0.381 \\
\hline 4 & 0.333 & -6.765 & 5.28 & 13.09 & -23.37 & -0.402 \\
\hline 5 & 0.461 & -9.303 & 6.62 & 13.12 & -36.86 & -0.503 \\
\hline 6 & 0.582 & -9.870 & 7.09 & 13.10 & -33.96 & -0.519 \\
\hline 7 & 0.695 & -9.412 & 1.33 & 13.14 & -56.59 & -0.531 \\
\hline 8 & 0.801 & -6.813 & 2.78 & 13.33 & -23.60 & -0.447 \\
\hline 9 & 0.904 & -7.034 & 1.98 & 13.54 & -34.65 & -0.914 \\
\hline 10 & 1.000 & 0.000 & 0.00 & 13.56 & 0.00 & -0.000 \\
\hline
\end{tabular}

Table 4

(Cabontetrachloride + Benzaldehyde) $308.15 \mathrm{~K}$

\begin{tabular}{|c|c|c|c|c|c|c|}
\hline obs & $\mathrm{X}_{1}$ & $\eta^{E}\left(10^{-5} \mathrm{NSm}^{-2}\right)$ & $V^{E}\left(10^{6} \mathrm{~m}^{3}\right)$ & $\mathrm{G}(\mathrm{KJ} / \mathrm{mole})$ & $G^{E}($ KJ / mole $)$ & $\mathrm{d}$ \\
\hline 1 & 0.000 & 0.00 & 0.000 & 14.972 & 0.00 & 0.000 \\
\hline 2 & 0.113 & -4.10 & 0.088 & 14.653 & -11.95 & -0.015 \\
\hline 3 & 0.295 & -8.70 & 0.009 & 14.395 & -23.04 & -0.031 \\
\hline 4 & 0.376 & -1.20 & 3.260 & 14.450 & -22.60 & -0.022 \\
\hline 5 & 0.427 & -1.25 & 3.280 & 14.245 & -24.89 & -0.067 \\
\hline 6 & 0.505 & -1.14 & 3.320 & 14.188 & -35.89 & -0.082 \\
\hline 7 & 0.601 & -8.20 & 2.790 & 14.186 & -57.69 & -0.085 \\
\hline 8 & 0.741 & -5.60 & 0.780 & 13.847 & -48.38 & -0.064 \\
\hline 9 & 0.890 & -2.10 & 0.800 & 13.721 & -40.74 & -0.037 \\
\hline 10 & 1.000 & 0.00 & 0.000 & 13.566 & 0.00 & 0.000 \\
\hline
\end{tabular}




\section{I.S. Jha et. al}

Table 5

(Cabontetrachloride + Isodutylmethylketone) $308.15 \mathrm{~K}$ (Redlick-Kister Equation)

\begin{tabular}{|c|c|c|c|c|c|c|c|}
\hline obs & $\mathrm{X}_{1}$ & $\begin{array}{c}\eta^{\mathrm{E}} \\
\left(10^{-6} \mathrm{Nsm}^{-2}\right)\end{array}$ & $\begin{array}{c}\delta \eta^{\mathrm{E}} \\
\left(10^{-5} \mathrm{Nsm}^{-2}\right)\end{array}$ & $\begin{array}{c}\mathrm{V}^{\mathrm{E}} \\
\left(10^{-6} \mathrm{~m}^{3}\right)\end{array}$ & $\begin{array}{c}\delta \mathrm{V}^{\mathrm{E}} \\
\left(10^{-6} \mathrm{~m}^{3} / \mathrm{mole}\right)\end{array}$ & $\begin{array}{c}\mathrm{G}^{\mathrm{E}} \\
(\mathrm{KJ} / \mathrm{mole})\end{array}$ & $\begin{array}{c}\delta \mathrm{G}^{\mathrm{E}} \\
(\mathrm{KJ} / \mathrm{mole})\end{array}$ \\
\hline 1 & 0.000 & 0.000 & 0.0 & 0.00 & 0.00 & 0.00 & 0.000 \\
\hline 2 & 0.143 & -6.701 & -1.7 & 0.46 & -0.10 & -28.68 & 0.0037 \\
\hline 3 & 0.234 & -5.038 & -2.4 & 1.27 & -1.04 & -31.88 & -0.0020 \\
\hline 4 & 0.333 & -6.765 & -3.2 & 5.28 & -0.88 & -23.37 & 0.0082 \\
\hline 5 & 0.461 & -9.303 & -5.9 & 6.62 & -0.54 & -36.86 & 0.0033 \\
\hline 6 & 0.582 & -9.870 & -2.8 & 7.09 & -1.10 & -33.96 & 0.0037 \\
\hline 7 & 0.695 & -9.412 & -1.5 & 1.33 & -3.04 & -56.59 & -0.0015 \\
\hline 8 & 0.801 & -6.813 & -1.4 & 2.78 & -0.61 & -23.60 & -0.0037 \\
\hline 9 & 0.904 & -7.034 & -1.7 & 1.98 & -1.63 & -34.65 & -0.0063 \\
\hline 10 & 1.000 & 0.000 & 0.00 & 0.00 & 0.00 & 0.00 & 0.0000 \\
\hline
\end{tabular}

Table 6

(Cabontetrachloride + Benzaldehyde) 308.15 K (Redlick-Kister Equation)

\begin{tabular}{|c|c|c|c|c|c|c|c|}
\hline obs & $\mathrm{X}_{1}$ & $\begin{array}{c}\eta^{\mathrm{E}} \\
\left(10^{-6} \mathrm{Nsm}^{-2}\right)\end{array}$ & $\begin{array}{c}\delta \eta^{\mathrm{E}} \\
\left(10^{-5} \mathrm{Nsm}^{-2}\right)\end{array}$ & $\begin{array}{c}\mathrm{V}^{\mathrm{E}} \\
\left(10^{-6} \mathrm{~m}^{3}\right)\end{array}$ & $\begin{array}{c}\delta \mathrm{V}^{\mathrm{E}} \\
\left(10^{-6} \mathrm{~m}^{3} / \mathrm{mole}\right)\end{array}$ & $\begin{array}{c}\mathrm{G}^{\mathrm{E}} \\
(\mathrm{KJ} / \mathrm{mole})\end{array}$ & $\begin{array}{c}\delta \mathrm{G}^{\mathrm{E}} \\
(\mathrm{KJ} / \mathrm{mole})\end{array}$ \\
\hline 1 & 0.000 & 0.00 & 0.00 & 0.000 & 0.0000 & 0.00 & 0.0000 \\
\hline 2 & 0.113 & -4.10 & 0.08 & 0.088 & -0.0004 & -11.95 & 0.0016 \\
\hline 3 & 0.295 & -8.70 & 1.10 & 0.009 & -0.0014 & -23.04 & 0.0029 \\
\hline 4 & 0.376 & -1.20 & -0.90 & 3.260 & -0.0008 & -22.60 & -0.0003 \\
\hline 5 & 0.427 & -1.25 & -1.10 & 3.280 & -0.0004 & 24.89 & -0.0049 \\
\hline 6 & 0.505 & -1.14 & -0.30 & 3.320 & -0.0002 & -35.04 & -0.020 \\
\hline 7 & 0.601 & -8.20 & 1.30 & 2.790 & -0.0001 & -57.69 & -0.0113 \\
\hline 8 & 0.741 & -5.60 & 0.08 & 0.780 & -0.0008 & -48.38 & -0.0057 \\
\hline 9 & 0.890 & -2.10 & 7.60 & 0.800 & -0.0008 & -40.74 & -0.0009 \\
\hline 10 & 1.000 & 0.00 & 0.00 & 0.000 & 0.0000 & 0.00 & 0.0000 \\
\hline
\end{tabular}

Table 7

(Least Square Parameters)

\begin{tabular}{|c|c|c|c|c|c|c|c|c|}
\hline \multirow{2}{*}{ Parameter } & \multicolumn{4}{|c|}{$\mathrm{CCl4}+\mathrm{BD}$} & \multicolumn{4}{c|}{$\mathrm{CCl4}+\mathrm{IBMK}$} \\
\cline { 2 - 9 } & $\mathrm{A}$ & $\mathrm{B}$ & $\mathrm{C}$ & $\sigma$ & $\mathrm{A}$ & $\mathrm{B}$ & $\mathrm{C}$ & $\sigma$ \\
\hline$\eta^{\mathrm{E}}$ & -0.0044 & 0.0017 & 0.0028 & 0.00008 & -0.0034 & -0.0016 & -0.0008 & 0.0008 \\
\hline $\mathrm{V}^{\mathrm{E}}$ & 0.0125 & 0.0034 & 0.0034 & 0.00070 & 0.0240 & 0.0033 & -0.0302 & 0.0156 \\
\hline $\mathrm{G}^{\mathrm{E}}$ & 0.1460 & 0.194 & 0.1780 & 0.00510 & -0.1390 & -0.0610 & -0.2110 & 0.0078 \\
\hline
\end{tabular}


BIBECHANA

Vol. 6, March 2010

\section{Result and Discussion}

The basic data of both the systems of binary mixtures $\mathrm{CCl}_{4}+$ IBMK (System I) and $\mathrm{CCl}_{4}+$ BD (System II) have been given in tables 1 and 2. The observations have been recorded at $308.15 \mathrm{~K}$. The required parameters and their excess values have been calculated using equation (i) to (ii). To fit Redlich-Kister equation for the prediction of excess values and their standard deviations, the constants for the systems I and II have been calculated by least square fit methods. The calculated values have been recorded in table 3 to 7 .

Perusal of table 1 and 2 of both the systems indicate that the magnitude of the viscosities decreases in systems II and increases in system I at the same temperature as the concentration of $\mathrm{CCl}_{4}$ increases. The magnitude of densities increases in both the systems with the increase in concentration of $\mathrm{CCl}_{4}$

In order to study the relative interaction in above systems, we have made use of excess parameters $\eta^{\mathrm{E}}, \mathrm{V}^{\mathrm{E}}$ and $\mathrm{G}^{\mathrm{E}}$. For ideal mixing the excess values should be zero. The deviation, whether positive or negative indicate the non-ideality of the mixtures. The deviation from the ideal behaviour in the mixtures i.e., non-zero values of excess parameters are due to presence of interactions between the constituents of the mixtures. These interactions are of various types. The positive values of excess volume attributed to dispersive forces while negative values of excess derived parameters have been attributed to charge transfer, hydrogen bonding, dipole-dipole and dipole induced dipole interaction [17]. Thus we conclude that dispersive forces operate in both the systems. But if additional interactions are also present between the components of the mixtures then the excess values of the derived parameters are the net results of all types of contributions.

The non-zero values of different excess parameters in both the systems of mixtures shown in the table 3 and 4 confirm the presence of specific interactions between the components of the mixtures. Attempts have been made by various workers $[18,19]$ to explain the nature and strength of such interactions on the basis of sign and magnitude of excess parameters. If strong interaction is present in a mixture then the molecules of the components come closer after mixing. This will cause a decrease in volume compared to what is expected for an ideal case, $\mathrm{V}^{\mathrm{E}}$ then will be negative. The excess volume $\mathrm{V}^{\mathrm{E}}$, interactions in the systems. The perusal of the sign and magnitude of the excess volume parameter shows that the interaction in the systems follows the following order :

$$
\mathrm{CCl}_{4}+\mathrm{IBMK}>\mathrm{CCl}_{4}+\mathrm{BD}
$$

The negative deviation of $\eta^{\mathrm{E}}$ for both the systems indicates that dispersive forces are primarily responsible for interaction [20]. Also the negative deviation of $\eta^{\mathrm{E}}$ implies that the dipole interactions are more probable in these systems. Further the negative deviations in excess values of the activation of energy flow also indicate the decrease in the internal energy of viscous flow, thus supporting the presence of weak interaction in the systems studies [21], the sign and magnitude o the Nissan-Grunberg parameter ' $d$ ' has been taken as the measure of the strength of interactions. The negative values of the parameter (d) shows the presence of weak interaction in the systems.

Thus the study of the table 1 to 4 shows that the systems under study contain dispersive interactions of weak magnitude and their strength of interaction can be placed in the following order :

$$
\mathrm{CCl}_{4}+\mathrm{IBMK}>\mathrm{CCl}_{4}+\mathrm{BD}
$$

Further, we have fitted the Redlich-kister equations for parameters $\eta^{\mathrm{E}}, \mathrm{V}^{\mathrm{E}}$ and $\mathrm{G}^{\mathrm{E}}$ by using least square fit method. The result has been given in table 5, 6 and 7. We found that our results are satisfactory by comparing the results of other workers [22]. 
I.S. Jha et.al

\section{References}

1. H.N.V. Temperley, J.S. Rawlinson, and G.S. Rushbroke, Physics of simple liquids , John Wiley, New York, (1968).

2. $\quad$ D.D .Despandev and , L.G., Bhutangade, Phy. Chem 71, (1967) 1277.

3. $\quad$ R.P. Rastogi., and J.J.Misra, Phys.Chem 71, (1967) 1277.

4. J.K. Halzhaverand W.T. Zeigler, J. Phys. Chem ,79, (1975) 590.

5. $\quad$ Fort. R.J. and W.R. ,Traus Faraday Soc. (GB), 61 (1975) 2105.

6. V.Tiwari, \& J.D. Pandey, Indian. J. Pure \& Appl. Phys. 18, (1980) 51.

7. V.A. Tabhane, V. N.Badhe, and B. A., Pataki, , Accustica (Gev) 411.

8. V.A. Tabhane, V.A Badhe and B.A Pataki,., Ind. J. pure \& Appl. Phys. 20 (1982) 159.

9. D.V.S. Jain, M. Alstair, and A. Pethrie, Trans. Faraday Soc. (GB) 70, (1974) 1293.

10. D. Dalwoska, A. Dutkiewitz \& Surma, D. ACTA. Phys. 15, (1977) 719.

11. R.L. Misra. and J.D. Pandey, Ind. J. Pure \& Appl. Phys. 15, (1977) 870.

12. G. Maijano, and F.J. Wandereingh, Chem.Phys. (USA) 69,(1978)559.

13. H. Eyring, and Hirschfelder., J. Phys. Chem.41, (1937) 249.

14. S. Glasstone, K.J. Laider, and H. Eyring, The theory of rate process, Mc Grow Hill, NY (1941).

15. C.R.C Table (1960).

16. J.D., Pandey, G.P. Dubey, B.P. Shukla, and S.N.J. Dubey, Ultrasonic 13, (1991) 74.

17. V.A., Tavhane, and B.A Pataki, Ind. J.Pure \& Appl. Phys 22, 447(1984).

18. K.M. Singh, V.K. Mishra, S.N. Sudhanshu and T. Sati, Proc. Solid State Phys. Sympo.(India),33, (1991) 296.

19. O. Prakash, J. Raman, T. and E. Rajgopal, Ind. J. Pure \& Appl. Phys. 26, 716(1988).

20. R.K.Nigam,. and B.S. Maki Ind. J. Chem. 9(1971)1255.

21. M. Chauhan, R. Mishra, and A. Singh, , Pramana 20, (1983)77.

22. A Kumar., N. Pitamber, and S. Prakash, Ind. J. Pure \& Appl.Phys. 32, 608(1984). 